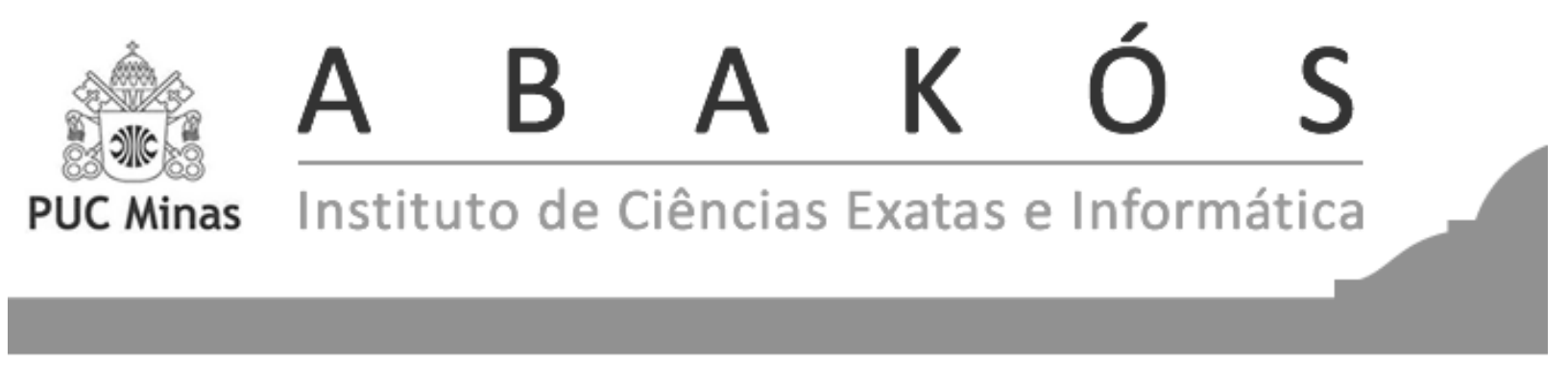

\title{
Por que existe o dia e a noite? Uma proposta de ensino interdisciplinar em museu interativo*
}

Why is there day and night? A proposal for interdisciplinary teaching in an interactive museum

Diego de Vargas Matos ${ }^{1}$

Ana Lúcia Purper Thiele ${ }^{2}$

Isabel Cristina Machado de Lara $^{3}$

José Luis Ferraro ${ }^{4}$

\begin{abstract}
Resumo
Este artigo apresenta o relato de experiência advindo da realização de um projeto de ensino interdisciplinar acerca do tema Rotação da Terra com estudantes de quinto ano do Ensino Fundamental de uma escola pública de Porto Alegre, RS. Objetiva verificar as mudanças na percepção dos estudantes acerca do motivo da existência do dia e da noite na Terra ocasionada pela exploração de recursos disponibilizados por um museu interativo. Para tanto, foi realizada uma pesquisa qualitativa analisando e comparando as respostas dadas pelos estudantes a um pré e pós questionário por meio da Análise Textual Discursiva. Utilizou-se a Modelagem Matemática como método de ensino e um museu interativo como espaço não formal de educação durante a realização do projeto. Evidencia que a exploração de museus interativos aliada à utilização da Modelagem Matemática como método de ensino causou uma mudança significativa na percepção que os estudantes tinham sobre a existência do dia e da noite na Terra. Além disso, aponta a eficácia de projetos interdisciplinares de ensino para aprimorar a visualização e a compreensão dos estudantes a respeito do mundo em que vivem.
\end{abstract}

\footnotetext{
*Submetido em 26/04/2017 - Aceito em 20/02/2018

${ }^{1}$ Licenciado em Matemática e Mestre em Educação em Ciências e Matemática, pela Pontifícia Universidade Católica do Rio Grande do Sul (PUCRS), Brasil- diego.matos@acad.pucrs.br

${ }^{2}$ Graduada em Pedagogia - Habilitação em Supervisão Escolar e em Magistério das Matérias Pedagógicas do Ensino Médio, pelas Unidades Integradas de Ensino Superior do Vale do Jacuí, e Mestre em Educação em Ciências e Matemática, pela Pontifícia Universidade Católica do Rio Grande do Sul (PUCRS), Brasil- ana.thiele@acad.pucrs.br ${ }^{3}$ Licenciada em Matemática, Mestre e Doutora em Educação, pela Universidade Federal do Rio Grande do Sul (UFRGS), e Pós-Doutoramento em Educação em Ciências e Matemática pela Pontifícia Universidade Católica do Rio Grande do Sul (PUCRS), Brasil- isabel.lara@ pucrs.br

${ }^{4}$ Licenciado em Ciências Biológicas, Mestre em Biologia Celular e Molecular e Doutor em Educação, pela Pontifícia Universidade Católica do Rio Grande do Sul (PUCRS), Brasil- jose.luis@ pucrs.br
} 
Palavras-chave: Interdisciplinaridade. Museu Interativo. Modelagem Matemática. Rotação da Terra. Ensino Fundamental. 


\begin{abstract}
This paper presents an account of results of an interdisciplinary educational project on the theme of Earth Rotation with students of a class of fifth grade at a public elementary school in Porto Alegre, RS. It aims to verify the changes in the students' perception about the reason for the existence of day and night on Earth occasioned by the exploration of resources made available by an interactive museum. Therefore, qualitative research was done by analyzing and comparing the answers given by students to a pre and a post-questionnaire. Mathematical Modeling was used as the teaching method and a museum as a non-formal space of education during the project realization. It shows that the exploration of interactive museums allied to the use of Mathematical Modeling as a method of teaching caused a significant change in students' perception of the existence of day and night on Earth. Besides, it points to the effectiveness of using interdisciplinary projects to improve students' visualization and comprehension about the world they live in.
\end{abstract}

Keywords: Interdisciplinarity. Interactive Museum. Mathematic Modeling. Earth Rotation. Elementary School. 


\section{INTRODUÇÃO}

De acordo com o artigo $5^{\circ}$ da Resolução CNE/CP, $n^{\circ}$ 1, de 15 de maio de 2006, o professor dos Anos Iniciais do Ensino Fundamental, com formação em curso superior de Pedagogia, deverá estar apto a: [...] ensinar Língua Portuguesa, Matemática, Ciências, História, Geografia, Artes, Educação Física, de forma interdisciplinar e adequada às diferentes fases do desenvolvimento humano". No entanto, muitos docentes dessa etapa da Educação Básica têm dificuldade em abordar diferentes disciplinas de maneira integrada em uma mesma proposta didática. Quando conseguem, geralmente, a disciplina de Matemática fica em segundo plano, pois os próprios professores tendem a não visualizar sua presença em diversos temas cotidianos, o que acaba afetando sua aprendizagem pelos estudantes.

Pensando nisso, elaborou-se um projeto de ensino interdisciplinar envolvendo as disciplinas de Artes, Ciências, Geografia, Língua Portuguesa e Matemática durante o estudo do tema Rotação da Terra com estudantes de uma turma de quinto ano do Ensino Fundamental de uma escola pública do município de Porto Alegre, RS. O objetivo foi verificar os possíveis impactos da exploração dos recursos disponibilizados pelo Museu de Ciências e Tecnologia da Pontifícia Universidade Católica do Rio Grande do Sul (MCT-PUCRS) como museu interativo na percepção dos estudantes a respeito do motivo de existência do dia e da noite na Terra. O projeto foi elaborado a partir dos princípios da Modelagem Matemática como método de ensino, que, segundo Biembengut e Hein (2011), “[...] norteia-se por desenvolver o conteúdo programático a partir de um tema ou modelo matemático e orientar o estudante na realização de seu próprio modelo-modelagem" (p.18). Neste projeto, o modelo a ser construído foi de uma maquete que descrevesse o movimento de rotação da Terra. A partir disso, realizou-se uma pesquisa de abordagem qualitativa utilizando como sujeitos os estudantes envolvidos no projeto. Os dados para análise foram coletados a partir de suas respostas à questão "Por que existe o dia e a noite?" em dois momentos distintos: antes e depois da realização do projeto. As respostas prévias e posteriores foram analisadas com inspiração no método de análise defendido por Moraes e Galiazzi (2011), a Análise Textual Discursiva - ATD, na tentativa de averiguar as contribuições do uso de um museu interativo como o MCT-PUCRS para a alfabetização científica dos estudantes envolvidos.

\section{ALGUNS APORTES TEÓRICOS}

Conforme Santomé (1998, p.73), a interdisciplinaridade

[...] reúne estudos complementares de diversos especialistas em um contexto de estudos de âmbito mais coletivo. A interdisciplinaridade implica em uma vontade e compromisso de elaborar um contexto mais geral, no qual cada uma das disciplinas em contato são por sua vez modificadas e passam a depender claramente umas das outras. 
Desse modo, a interdisciplinaridade surge para combater o ensino disciplinar fragmentado visto que o conhecimento deve ser construído como um todo e não em partes. Para tanto, deve haver diálogo e relação de dependência entre as diferentes disciplinas. Essa ideia é da maior relevância uma vez que os problemas enfrentados na realidade estão inseridos em um contexto mais amplo que ultrapassa os limites de uma única disciplina. Corroborando, Santomé (1998, p.73-74) afirma que “[...] alunos e alunas com uma educação mais interdisciplinar estão mais capacitados para enfrentar problemas que transcendem os limites de uma disciplina concreta e para detectar, analisar e solucionar problemas novos" (SANTOMÉ, 1998).

Vale ressaltar ainda o que Ferraro e Giglio (2014, p.344) afirmam: "É na percepção onde tudo se relaciona com tudo que o conhecimento do aluno se forja de maneira mais plástica e passa a ser mobilizado de maneira rápida em resposta aos problemas cotidianos" (FERRARO; GIGLIO, 2014).

A interdisciplinaridade pode ser desenvolvida em diferentes espaços, inclusive espaços não formais de educação, como, por exemplo, um museu. É aconselhável que os professores proponham atividades que ultrapassem as paredes da sala de aula e, assim, possam despertar maior atenção e interesse dos estudantes e levá-los a conhecer outros espaços que colaborem para a sua aprendizagem.

O museu pode tornar-se aliado dos processos de ensino e de aprendizagem desde que seja explorado adequadamente por professores e estudantes, pois os recursos que possui, entre outros ganhos, possibilitam a visualização de conteúdos abordados em aula. Segundo o Comitê Internacional de Museus (ICOM) na definição aprovada pela 20a Assembléia Geral realizada em Barcelona, Espanha, em 6 de julho de 2001:

Um museu é uma instituição permanente, sem fins lucrativos, a serviço da sociedade e do seu desenvolvimento, aberta ao público e que adquire, conserva, investiga, difunde e expõe os testemunhos materiais do homem e de seu entorno, para educação e deleite da sociedade (COMITÊ, 2001).

Os recursos disponíveis em um museu possuem elementos de diferentes disciplinas. Desse modo, o museu pode tornar-se também um espaço adequado para o desenvolvimento de uma proposta interdisciplinar de ensino. Além disso,

A parceria estabelecida entre museus e escolas se constitui em ganho na aprendizagem por parte dos alunos, tornando-os mais protagonistas de seu próprio processo de ensino, além de instigá-los a resolver problemas que aparecem no caso específico de um museu de ciências - no funcionamento dos próprios experimentos (FERRARO; GIGLIO, 2014, p. 334-335).

No caso específico de um museu de ciências, ele torna-se um espaço adequado para auxiliar na alfabetização científica dos estudantes. De acordo com Chassot (2003, p.91): “A ciência pode ser considerada como uma linguagem construída pelos homens e pelas mulheres para explicar o nosso mundo natural”.

Chassot (2003) também acredita que entender a ciência facilita e contribui para que homens e mulheres possam controlar e prever as transformações que ocorrem na natureza de 
modo que sejam propostas para que conduzam a uma melhor qualidade de vida. Ainda segundo o autor, embora a ciência torne o mundo inteligível, esse é - e existe - independente da ciência e a tecnologia, como aplicação da ciência, modifica esse mundo. Nesse sentido, a alfabetização científica é o conjunto de conhecimentos que facilitam aos homens e mulheres fazer uma leitura do mundo onde vivem. E o analfabeto científico é justamente aquele incapaz de realizar essa leitura (CHASSOT, 2003).

O autor ressalta a importância dos alfabetizados cientificamente perceberem a necessidade de utilizar seus conhecimentos em prol de uma melhora na qualidade de vida no mundo quando afirma que: "Seria desejável que os alfabetizados cientificamente não apenas tivessem facilitada a leitura do mundo em que vivem, mas entendessem as necessidades de transformá-lo - e, preferencialmente, transformá-lo em algo melhor" (CHASSOT, 2003, p. 94). A tecnologia, como aplicação da ciência, surge como uma ferramenta para contribuir para essas transformações.

Buscando colaborar para a alfabetização científica de homens e mulheres, os chamados museus de ciências e tecnologia promovem acesso a conhecimentos científicos e tecnológicos simultaneamente. De acordo com Valente, a museologia de ciências e tecnologia

[...] é desafiada a assegurar a função tradicional dos museus de preservar e estudar um patrimônio, material e imaterial, ao mesmo tempo em que enfrenta questões e relações criadas na atualidade pela ciência e tecnologia, que transformam em ritmo acelerado o ambiente da sociedade (VALENTE, 2007, p. $11)$.

Alguns museus, em particular de ciências e tecnologia, são considerados interativos, pois possibilitam a ação dos visitantes sobre os experimentos, explorando os recursos disponibilizados. Desse modo, os visitantes podem tocar, experimentar e observar os fenômenos de diversas áreas do conhecimento humano. Além disso, vale destacar que o conhecimento construído a partir dessa interação envolve o prazer de uma descoberta (BERTOLETTI, 2013).

O MCT-PUCRS é um exemplo de museu interativo. Inaugurado em 14 de dezembro de 1998, a sua nova exposição, estruturada em uma área total de $22.000 \mathrm{~m}^{2}$, incluindo os anexos,

[...] é composta por 23 áreas do conhecimento, com conteúdos variados e representados por 700 experimentos interativos e expositivos para todas as idades e interesses. As áreas são denominadas da seguinte forma: Desafio com Figuras e Números; Força e Movimento; Fluídos; Luz; Ondas e Som; Calor; Eletricidade e Magnetismo; Matéria e Energia; Comunicação; Tecnologia; Universo; Planeta Terra; Milhões de Anos; Dioramas; Educação Ambiental; Ser Humano; Mundo Microscópico; Seres Vivos; No Passado; Interações Vivas; Mundo da Criança; Saúde; e Galeria de Gênios (BERTOLETTI, 2013, p. 25).

No entanto, antes de tornar-se Museu de Ciências e Tecnologia, esse museu já obteve outras denominações devido às diversas modificações que sofreu ao longo do seu período de existência. São elas: Museu de Zoologia, Museu de História Natural e Museu de Ciências. Sua origem, desenvolvimento e continuidade estão intrinsecamente relacionados ao trabalho de 
Jeter Jorge Bertoletti, seu diretor de 1967 a 2007. Inicialmente, o museu contava apenas com coleções de rochas, minerais e animais empalhados. Algumas dessas coleções foram adquiridas de material zoológico, outras do próprio acervo particular de Bertoletti. Porém, com o tempo, foi adquirindo mais materiais como peixes de água doce, material paleontológico, experimentos interativos de física, entre outros (BERTOLETTI, 2012).

Segundo Bertoletti (2012), o MCT-PUCRS, com a missão de aproximar as pessoas da ciência e da tecnologia de maneira a atingir uma compreensão mais plena da realidade, apresenta seus principais objetivos. São eles:

despertar e desenvolver o espírito científico e tecnológico da população em geral; popularizar a ciência e a tecnologia através da alfabetização científica, em um processo de inclusão social a partir do sistema de aprendizagem desenvolvido no MCT; contribuir para a melhoria no ensino formal e informal de ciências e matemática; contribuir para a melhoria na formação de professores; capacitar técnicos, especialistas e pesquisadores; produzir materiais e programas educativos; estabelecer intercâmbios com instituições congêneres; incrementar a pesquisa científica tanto básica quanto aplicada (BERTOLETTI, 2012, p. 319).

Nesse sentido, o projeto de ensino interdisciplinar relatado neste trabalho com vistas a atingir alguns dos objetivos apresentados, mas, principalmente, colaborar para a alfabetização científica dos estudantes envolvidos, contou com uma visita ao MCT-PUCRS e com a realização de roteiro de atividades de exploração dos recursos disponíveis nesse espaço durante sua execução. Para tanto, utilizou-se a Modelagem Matemática como método de ensino.

Bassanezi (2009, p.24), define modelagem como "[...] um processo dinâmico utilizado para obtenção e validação de modelos matemáticos". Segundo o autor, a essência da Modelagem Matemática está “[...] na arte de transformar situações da realidade em problemas matemáticos cujas soluções devem ser interpretadas na linguagem usual" (p.24). No caso da proposta de ensino, a situação real foi o movimento de rotação da Terra problematizado a partir do questionamento: "Por que existe o dia e a noite?".

Modelo matemático é entendido por Bassanezi (2009, p.20) como “[...] um conjunto de símbolos e relações matemáticas que representam de alguma forma o objeto estudado". Essa representação pode ocorrer por meio de desenho, projeto, esquema, gráfico, lei matemática, dentre outras formas (BIEMBENGUT, 2014). No projeto interdisciplinar relatado neste trabalho, essa representação ocorreu por meio das maquetes que os estudantes construíram buscando representar o movimento de rotação da Terra (BASSANEZI, 2009).

Conforme Biembengut (2014, p.21): "Modelagem é o processo envolvido na elaboração de modelo de qualquer área do conhecimento. Trata-se de um processo de pesquisa". Para a autora, “[...] a modelagem, arte de modelar, é um processo que emerge da própria razão e participa da nossa vida como forma de constituição e de expressão do conhecimento" (BIEMBENGUT, 2014, p.11).

A Modelagem Matemática, como perfaz o caminho da investigação científica, tem sido defendida como método de ensino e pesquisa, constituindo-se, assim, em forte área de pesquisa em Educação Matemática em muitos países (BIEMBENGUT, 2014). Lara e Biembengut 
afirmam que:

A defesa pela modelagem como método de ensino e aprendizagem em todos os níveis de escolaridade, em diversos países, tem aumentado significativamente, pelo fato de propiciar ao estudante fazer uso da matemática para compreender uma situação ou resolver um problema de outra área do conhecimento; isto é, integrar matemática a outra área do conhecimento e em especial, área que o estudante apresenta interesse (LARA; BIEMBENGUT, 2011, p.342).

Biembengut (2014) aponta três etapas para a realização da Modelagem Matemática, a saber: "Percepção e Apreensão"; "Compreensão e Explicitação"; "Significação e Expressão". Assim, ao elaborar um projeto de ensino é necessário que o professor fique atento para que os estudantes percorram todas as etapas.

$\mathrm{Na}$ "Percepção e Apreensão", os estudantes procuram perceber os entes envolvidos na situação problema por meio de estudo em livros, revistas especializadas, etc.; ou por meio de saídas de campo e dados experimentais adquiridos com especialistas da área. Conforme os estudantes percebem, se familiarizam, a situação problema torna-se mais clara e, então, é apreendida por eles. Vale ressaltar que, durante todo o processo de modelagem, os dados coletados nessa etapa serão utilizados (BIEMBENGUT, 2014).

$\mathrm{Na}$ “Compreensão e Explicitação", objetiva-se que os estudantes encontrem um modelo que lhes possibilite resolver a situação problema ou, então, deduzir sua solução. Para que isso ocorra, eles devem compreender a situação ou fenômeno investigado e propor um sistema conceitual visando à explicitação dos dados. Biembengut (2014, p.24) considera essa etapa a mais complexa e desafiante do processo de modelagem, pois exige dos estudantes: "[...] classificar as informações relevantes, formular as hipóteses ou pressupostos, identificar as constantes e variáveis envolvidas, selecionar os símbolos apropriados para essas variáveis e descrever as relações em termos matemáticos - modelo”. Ao final dessa etapa, os estudantes devem resolver a situação problema a partir do modelo encontrado e realizar a aplicação. Trata-se de compreender todos os conceitos e propriedades envolvidas no movimentode rotação da Terra, buscando recursos físicos para construir a maquete - modelo. Na construção da maquete, os conhecimentos de diferentes áreas serão necessários, fazendo com que os professores envolvidos auxiliem os estudantes a encontrarem as respostas para os possíveis questionamentos. Trata-se, portanto, da etapa em que os estudantes irão compreender como funciona o fenômeno analisado e como modelá-lo da maneira mais fidedigna possível (BIEMBENGUT, 2014).

$\mathrm{Na}$ “Significação e Expressão", é necessário que os estudantes interpretem e avaliem os resultados obtidos da aplicação e, em seguida, verifiquem a conformidade e a relevância da solução - a validação. Se o modelo encontrado atender às necessidades que lhe deram origem, os estudantes devem significá-lo descrevendo, deduzindo ou verificando outros fenômenos. Ao final, devem expressar todo o processo de modelagem por escrito para que, assim, demais pessoas interessadas no assunto possam conhecê-lo (BIEMBENGUT, 2014).

É importante esclarecer que essas etapas não são disjuntas. Ao decorrer do processo de modelagem pode-se retornar a etapas anteriores à que se está sempre que isso seja necessário.

Vale destacar que a Modelagem Matemática pode tornar-se um eficaz método de pes- 
quisa e ensino para aproximar a Matemática da realidade dos estudantes e que pode ser utilizada em diferentes níveis de escolaridade, nesse caso nos Anos Iniciais do Ensino Fundamental, desde que adequadamente. Por meio da modelagem, é possível que o estudante desenvolva sua capacidade de pesquisa e sua criatividade para criação de modelos. Desse modo, justifica-se seu uso como método de ensino no projeto interdisciplinar relatado neste trabalho.

\section{PROCEDIMENTOS METODOLÓGICOS}

Ao optar pela Modelagem Matemática como método de ensino, o projeto interdisciplinar foi estruturado conforme as três etapas desse método definidas por Biembengut (2014): "Percepção e Apreensão"; "Compreensão e Explicitação"; "Significação e Expressão" (BIEMBENGUT, 2014).

\subsection{Etapa 1 - "Percepção e Apreensão"}

\subsubsection{Primeiro momento: 1 período de aula (50 min)}

- Respostas prévias dos estudantes à questão "Por que existe o dia e a noite?" em uma folha em branco entregue pelos professores. Assim, as influências do projeto podem ser analisadas e ao seu término, a mesma questão será novamente respondida pelos estudantes;

- Apresentação em multimídia (PowerPoint) contendo algumas fotografias do MCTPUCRS e de seus experimentos com o intuito de motivar os estudantes para a visita a esse museu.

\subsubsection{Segundo momento: 3 periodos de aula ( $2 \mathrm{~h} 30 \mathrm{~min})$}

\subsubsection{Atividade com a esfera}

- Análise e descrição das características de uma esfera em acrílico pelos estudantes;

- Construção de um cartaz intitulado "O que se parece com uma esfera", contendo figuras de objetos semelhantes a uma esfera identificados pelos estudantes sobre uma mesa;

- Corte de uma esfera oca de isopor e de uma esfera maciça representada por uma laranja ao meio pelos professores, mostrando aos estudantes que, com essas secções esféricas, pode ser obtido, respectivamente, a circunferência e o círculo;

- Comparação do círculo e da circunferência pelos estudantes, buscando diferenciar essas figuras. 


\subsubsection{Atividade com círculos e circunferências}

- Distribuição de cinco círculos concêntricos de tamanhos e cores diferentes a cada grupo de cinco estudantes nomeados, do menor ao maior, de A, B, C, D e E. Esses círculos podem ser sobrepostos do maior ao menor;

- Construção do raio e do diâmetro da circunferência e análise da relação entre suas medidas pelos estudantes;

- Exploração com os estudantes da relação de inclusão entre os círculos concêntricos entregues de maneira que percebam que, no caso particular desse material, $\mathrm{A} \subset \mathrm{B} \subset \mathrm{C} \subset \mathrm{D} \subset$ E.

\subsubsection{Simulação de situações geográficas}

- Exploração com os estudantes da relação de inclusão entre os subespaços do continente americano a partir da observação de seu mapa. Desse modo, fazendo uma comparação entre essa atividade e a anterior, espera-se que os mesmos concluam que Porto Alegre $\subset$ Rio Grande do Sul $\subset$ Brasil $\subset$ América do Sul $\subset$ América.

\subsubsection{Terceiro momento: 4 períodos de aula (3h 20min)}

- Visita ao MCT-PUCRS com o intuito de que os estudantes realizem, em grupos, as atividades descritas no roteiro de visita entregue a eles pelos professores. Essas atividades envolvem a exploração dos experimentos interativos 1108 Gira e gera, 2215 Sistema Sol, Terra e Lua e $2303 \mathrm{O}$ globo terrestre do MCT-PUCRS objetivando, principalmente, que os estudantes possam: a) relacionar o eixo da circunferência e o da esfera aos seus respectivos diâmetros; b) relacionar o formato da Terra a uma esfera; c) descrever o movimento de rotação da Terra; d) reconhecer a finalidade do eixo da Terra para o seu movimento de rotação; e) reconhecer que existe o dia e a noite devido ao movimento de rotação da Terra.

O experimento 1108 Gira e gera permite ao visitante apertar botões correspondentes a três figuras diferentes e observar qual sólido geométrico é gerado pela revolução de cada uma delas.

O experimento 2215 Sistema Sol, Terra e Lua proporciona ao visitante observar os movimentos de rotação e translação da Terra após apertar um botão que aciona esse comando. Também há uma placa explicativa nesse experimento, relatando os fenômenos resultantes desses movimentos.

O experimento $2303 \mathrm{O}$ globo terrestre permite ao visitante obter informações a respeito do Planeta Terra, como, por exemplo, profundidade dos oceanos e área dos continentes, apertando botões que acendem telas contendo essas informações. 


\subsection{Etapa 2 - "Compreensão e Explicitação": 3 períodos de aula (2h 30min)}

- Reprodução do vídeo "Escala do Universo, comparação de tamanhos dos planetas e estrelas" ${ }^{5}$ com o intuito de que os estudantes percebam que, em suas maquetes, não será possível construir em escala a representação da Terra, da Lua e do Sol devido às diferenças de seus reais tamanhos.

- Construção pelos estudantes, em grupos, de uma maquete que explique a existência do dia e da noite na Terra, ou seja, o movimento de rotação da Terra.

\subsection{Etapa 3 - "Significação e Expressão": 1 período de aula (50min)}

- Exposição das maquetes confeccionadas pelos grupos, utilizando-as como recurso para explicar aos demais colegas o motivo pelo qual existe o dia e a noite na Terra. Desse modo, é possibilitada a cada grupo a validação da maquete que construíram como modelo matemático encontrado, verificando se atende à necessidade que o originou, ou seja, se é capaz de responder à questão "Por que existe o dia e a noite?".

- Produção individual de um pequeno texto pelos estudantes, buscando responder novamente à questão "Por que existe o dia e a noite?". O intuito é verificar quais contribuições - a partir das atividades desenvolvidas no projeto interdisciplinar, em particular as realizadas no MCT-PUCRS - forneceram conhecimento aos estudantes referente à existência do dia e da noite na Terra.

\section{SÍNTESE DAS OCORRÊNCIAS}

Participaram da execução do projeto 26 estudantes de uma turma de quinto ano do Ensino Fundamental de uma escola pública estadual, localizada em Porto Alegre, RS, durante o horário de suas aulas. Eles desenvolveram as atividades propostas em grupos compostos por cinco estudantes.

Na Etapa 1, "Percepção e Apreensão", foram desenvolvidas atividades em sala de aula e no MCT-PUCRS. No primeiro momento dessa etapa, com o propósito de motivar os estudantes para a visita ao museu, foi exibido um vídeo contendo fotografias do mesmo e de seus experimentos. Apesar de alguns estudantes afirmarem que já visitaram o MCT-PUCRS em anos letivos anteriores, em geral, a turma demonstrou interesse pela proposta de realizar atividades novamente nesse museu.

Ainda nesse primeiro momento, solicitou-se a elaboração individual de pequenos textos em resposta à questão "Por que existe o dia e a noite?" para posterior análise.

No segundo momento dessa etapa, foram apresentados aos estudantes alguns sólidos

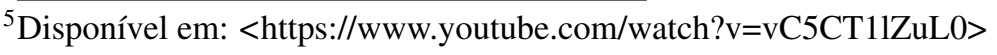


geométricos, entre eles, a esfera, o cubo, o cilindro e o cone. O intuito era que, analisando as diferenças da esfera em relação a outros sólidos geométricos, pudessem identificar suas características. Rapidamente, os estudantes perceberam que: a esfera pode rolar para todas as direções enquanto que o cilindro somente para uma; a esfera não possui lados e nem faces enquanto que o cubo sim; o cone possui uma ponta enquanto que a esfera não possui nenhuma.

Após esse reconhecimento inicial, foi elaborado um cartaz intitulado "O que se parece com uma esfera". Para tanto, foi solicitado a alguns estudantes que identificassem em uma mesa figuras de objetos semelhantes à esfera e as colassem no cartaz. Quando o objeto representado na figura não se assemelhava à esfera e, portanto, a figura não podia ser colada no cartaz, solicitava-se aos estudantes que apontassem qual dos demais sólidos geométricos sobre a mesa representava melhor esse objeto. Os estudantes demonstraram muito interesse por essa atividade e disputavam entre eles, de maneira organizada, quem seria escolhido pelos professores para colar as figuras no cartaz.

Durante a atividade com círculos e circunferências, para que eles pudessem perceber a diferença entre essas formas geométricas, foi realizado um corte ao meio em uma esfera oca de isopor e em uma esfera maciça representada por uma laranja, demonstrando que, com essas secções esféricas, obtém-se, respectivamente, a circunferência e o círculo. Após explicação complementar, os estudantes demonstraram compreender que círculo é a região limitada pelo contorno da figura enquanto que a circunferência é o contorno dessa figura.

Para a continuidade dessa atividade, foram distribuídos cinco círculos concêntricos para cada grupo de cinco estudantes. Solicitou-se a cada um que traçasse em um desses círculos uma reta do ponto de centro já marcado a um ponto qualquer da circunferência. Em seguida, solicitou-se que prolongassem essa reta até atingir o ponto oposto ao ponto da circunferência escolhido anteriormente. Assim, construíram o raio e o diâmetro desses círculos. Os estudantes não demonstraram dificuldade durante essa construção. Além disso, quando estimulados a verificar a relação existente entre raio e diâmetro, rapidamente conseguiram perceber que a medida do diâmetro corresponde ao dobro da medida do raio. Os círculos também foram auxiliares para a exploração das relações de inclusão entre conjuntos, uma vez que podiam ser sobrepostos do maior ao menor.

A partir dessas atividades com círculos e circunferências, foi possível perceber uma apropriação da linguagem matemática pelos estudantes, pois passaram a utilizar termos como círculo, circunferência, raio, diâmetro, contém, está contido, entre outros, demonstrando compreensão dos seus significados. Também, foi possível perceber uma melhora na visualização da presença da Matemática na realidade, quando conseguiram relacionar o centro da circunferência ao centro da laranja, afirmando que a Matemática está presente inclusive na natureza.

Para a última atividade do segundo momento, Simulação de situações geográficas, os professores apresentaram o mapa do continente americano para desenvolver com os estudantes a relação de inclusão dos subespaços desse continente. Foram pintados de diferentes cores os espaços no mapa do continente americano correspondentes à América do Sul, Brasil, Rio Grande do Sul e Porto Alegre. Desse modo, os estudantes tiveram um pouco de dificuldade em 
verificar a relação de inclusão entre esses territórios, mas, assim que foi feita uma relação com os círculos concêntricos utilizados na atividade anterior, os estudantes conseguiram perceber que Porto Alegre $\subset$ Rio Grande do Sul $\subset$ Brasil $\subset$ América do Sul $\subset$ América. Alguns estudantes ainda conseguiram continuar essa relação, afirmando que América $\subset$ Planeta Terra $\subset$ Sistema Solar $\subset$ Universo.

No terceiro momento da Etapa 1, ocorreu a visita orientada dos estudantes ao MCTPUCRS. Anteriormente à realização das atividades descritas no roteiro de visita elaborado pelos professores, os estudantes foram orientados a localizar um determinado experimento no museu, observando o número correspondente à área e ao próprio experimento. Também foram orientados a ler com bastante atenção as instruções contidas nas placas explicativas de cada experimento.

Após, o grupo dirigiu-se à área 1100 Desafios com figuras e números para explorar o experimento 1108 Gira e gera. Esse experimento possibilitou a visualização das superfícies geradas pela revolução das figuras. Solicitou-se aos estudantes que observassem a circunferência girar afim de que identificassem qual sólido geométrico seria gerado dessa maneira. Rapidamente, os estudantes identificaram que a esfera estava sendo gerada pela revolução da circunferência, pois já haviam explorado características desse sólido geométrico anteriormente em sala de aula. Observando o eixo abaixo da circunferência e imaginando que esse eixo se prolongasse até acima da circunferência coincidindo com o seu diâmetro, os estudantes conseguiram verificar que a circunferência somente gerou a esfera, pois girou em torno do seu eixo, ou seja, do seu diâmetro, e que, se esse eixo gerador não estivesse coincidindo com o seu diâmetro, não seria gerado o mesmo sólido geométrico. Os estudantes puderam comprovar sua resposta no mesmo experimento, a partir da revolução de duas circunferências menores ao lado da circunferência analisada em que o eixo gerador estava localizado entre elas, ou seja, não coincidia com o diâmetro de nenhuma delas, que geravam, nesse caso, uma espécie de anel.

Em seguida, dirigiram-se à área 2200 Universo localizada no segundo pavimento do MCT-PUCRS para explorar o experimento 2215 Sistema Sol, Terra e Lua. Esse experimento demonstra os movimentos de translação e rotação da Terra. No entanto, conforme roteiro de visita somente o movimento de rotação da Terra foi explorado. Os estudantes rapidamente identificaram que a Terra possui o formato de uma esfera. Quando solicitados a descrever o movimento realizado pelo planeta que estava sendo analisado, a maioria dos estudantes respondeu que "a Terra está girando em torno de si mesma". O nome do movimento os estudantes encontraram escrito na placa de instruções do experimento.

Observando o eixo abaixo da Terra e imaginando o prolongamento desse eixo até acima da Terra coincidindo com o seu diâmetro, os estudantes logo perceberam que a finalidade desse eixo é o movimento de rotação da Terra e que, portanto, durante sua ocorrência, a Terra gira em torno do seu próprio eixo. Para chegarem a essa conclusão, foram feitas relações com o experimento 1108 Gira e gera explorado anteriormente.

A maioria dos estudantes intuiu que o movimento de rotação da Terra está relacionado com a existência do dia e da noite. No entanto, ainda não tinham clareza do motivo. Assim, 
os estudantes foram orientados a observar o hemisfério da Terra em que está voltada a Lua no experimento e descrever o que acontecia quando esse hemisfério ficava voltado para o Sol e quando ficava oposto ao Sol conforme ocorria o movimento de rotação da Terra no experimento. Após observação atenta ao experimento e discussão com professores e colegas, muitos concluíram que o movimento de rotação da Terra é que gera o dia e a noite. Contudo, conforme anotações no roteiro de visita, foi possível perceber que alguns estudantes deixaram o museu acreditando que a Lua tivesse alguma relação com a existência do dia e da noite.

Por fim, foi explorado pelos estudantes o experimento $2303 \mathrm{O}$ globo terrestre localizado na área 2300 Planeta do segundo pavimento do MCT-PUCRS. Nele, os estudantes observaram o globo terrestre, identificaram os continentes e responderam - a partir das informações fornecidas pelo experimento - quantos e quais continentes há na Terra, qual o maior e o menor desses continentes e o que há entre eles. Os estudantes não demonstraram nenhuma dificuldade para realizar essa tarefa. Ao final da realização das atividades descritas no roteiro de visita ao MCTPUCRS, os estudantes puderam explorar livremente esse museu até o término do horário de visita.

Na etapa 2, "Compreensão e Explicitação", os estudantes, inicialmente, assistiram ao vídeo "Escala do Universo, comparação de tamanhos dos planetas e estrelas". Após, refletiram acerca do tamanho real dos planetas, satélites e estrelas que foram exibidos no vídeo, em particular os tamanhos da Terra, da Lua e do Sol. Nesse momento, foram questionados pelos professores se seria possível construir representações desses astros em escala em uma maquete. Para auxiliar nessa discussão, foram utilizadas as informações do experimento 2215 Sistema Sol, Terra e Lua explorado durante a visita ao MCT-PUCRS. Nesse experimento, era informado que o tamanho dos astros e a distância entre eles não estava em escala, pois a Terra, no experimento, possuía 6 centímetros de diâmetro e, portanto, o Sol deveria possuir 690 centímetros de diâmetro e a Lua, 1,8 centímetros de diâmetro, o que não acontecia. Os estudantes logo perceberam que não haveria uma esfera de isopor com tamanho de diâmetro suficiente para utilizar em suas maquetes. Desse modo, conseguiram concluir que não seria possível construir suas maquetes em escala. A solução encontrada pelos estudantes foi utilizar a esfera de isopor menor para representar a Lua, a esfera de isopor de tamanho médio para representar a Terra e a maior esfera de isopor possível para representar o Sol.

Após, organizados em cinco grupos, iniciaram a construção das maquetes que deveriam representar o movimento de rotação da Terra. O material utilizado para essa construção foi constituído de três esferas de isopor com tamanhos diferentes, três palitos de churrasco, uma placa de isopor e tintas guache de diversas cores. Neste texto, os cinco grupos de estudantes são denominados de A, B, C, D e E para melhor compreensão.

A maioria dos grupos preferiu utilizar a tinta preta para colorir a base da maquete, com exceção do grupo $\mathrm{C}$ que preferiu utilizar a cor azul. A escolha pela cor laranja para colorir o Sol foi quase unânime com exceção novamente do grupo $\mathrm{C}$ que utilizou a tinta de cor amarela. Observou-se que os estudantes buscaram utilizar cores aproximadas com as que visualizaram no vídeo assistido. A maioria dos grupos colou pequenos pedaços de isopor na base da maquete 
para representar as estrelas de maneira a realçá-las. Vale destacar, ainda, que todos os grupos coloriram a Terra de azul para representar os oceanos e de verde para representar os continentes.

Durante a construção das maquetes, o grupo B diferenciou-se dos demais, pois fixou a Lua na Terra por um palito, enquanto os outros grupos fixaram a Lua na base da maquete por um palito paralelo ao da Terra. Os grupos A, C e D mudaram sua maquete após observarem a maquete do grupo B. Nesse caso, verifica-se a influência do experimento 2215 Sistema Sol, Terra e Lua para a construção das maquetes dos grupos, pois possuía construção semelhante de modo que a Lua possa acompanhar a Terra enquanto esta realiza o seu movimento de rotação. Apenas o grupo E manteve sua construção inicial. Essas observações podem ser vistas na Figura 1.

Figura 1 - Maquete construída pelo grupo B e maquete construída pelo grupo E

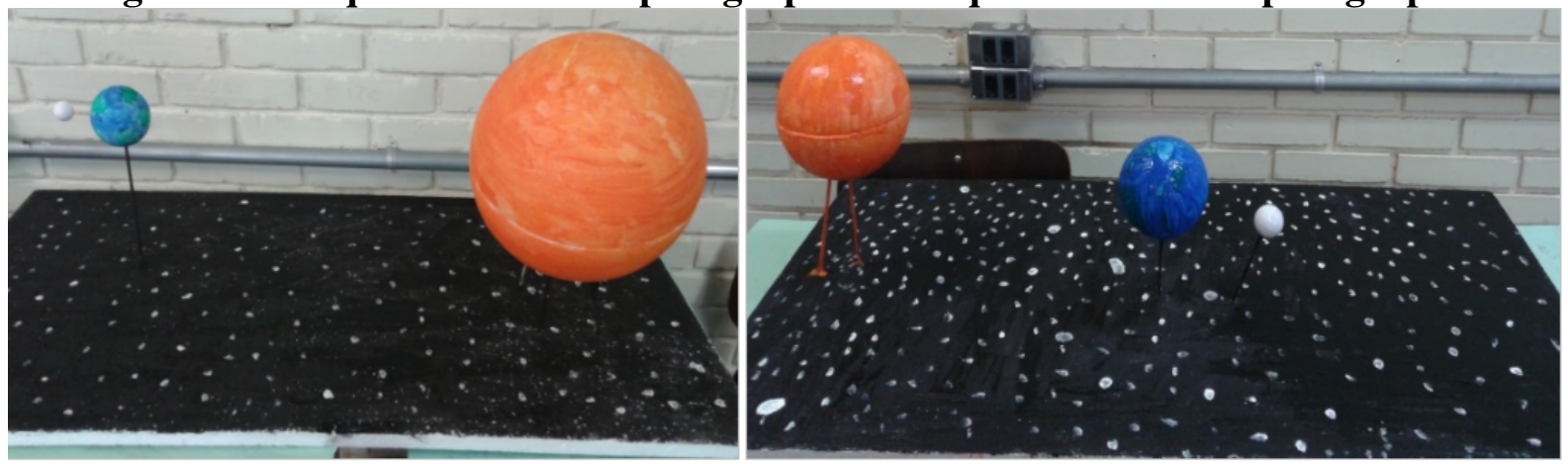

Fonte: Elaborada pelos autores (2017).

Durante a Etapa 3, "Significação e Expressão", ao apresentar sua maquete, um grupo havia utilizado dois palitos para fixar a Terra na base da maquete. No entanto, assim, a Terra não conseguia realizar seu movimento de rotação. Ao tentarem explicar a existência do dia e da noite na Terra, utilizando seu modelo como recurso, os estudantes logo perceberam esse erro e o corrigiram rapidamente, percebendo assim a importância do eixo da Terra para o seu movimento de rotação. Os demais grupos já haviam se dado conta disso durante a elaboração do modelo.

Ao final, todas as maquetes foram válidas como modelos matemáticos para representar a existência do dia e da noite na Terra. O modelo matemático que mais aproximou-se da realidade foi a maquete construída pelo grupo B tanto em relação ao tamanho dos astros quanto pela distância entre eles, pois conseguiram uma esfera de isopor maior para representar o Sol em comparação aos outros grupos e também porque deixaram distância maior entre o Sol e a Terra e distância menor entre a Terra e a Lua.

Ao término de todas as etapas, os estudantes elaboraram pequenos textos, respondendo novamente à questão "Por que existe o dia e a noite?". Por meio da análise desses dados, buscou-se identificar categorias que expressassem as implicações do projeto em suas percepções prévias. 


\section{ANÁLISE DOS RESULTADOS}

Para verificar as mudanças na percepção dos estudantes acerca do motivo da existência do dia e da noite na Terra, ocasionada pela exploração de recursos disponibilizados por um museu interativo, analisou-se, por meio da ATD, o texto construído para responder à pergunta: "Por que existe o dia e a noite?".

Para tanto, cada um dos textos foi fragmentado e, por meio da releitura de alguns excertos, escolheram-se unidades de significado que levaram à emergência de categorias. Os impactos poderão ser percebidos mediante a comparação dessas categorias emergentes.

Para exemplificar como a análise foi feita, no Quadro 1, foi exposto uma pequena amostra do modo como as categorias emergiram, apenas fragmentos de cinco dos vinte e cinco estudantes.

Quadro 1 - Algumas categorias emergentes do pré-questionário

\begin{tabular}{|c|c|c|c|}
\hline Excertos & Ressignificação & $\begin{array}{l}\text { Unidades de } \\
\text { Significado }\end{array}$ & $\begin{array}{l}\text { Categorias } \\
\text { Emergentes }\end{array}$ \\
\hline $\begin{array}{l}\text { E - Porque o dia é mais para } \\
\text { a gente aproveitar: fazer as } \\
\text { coisas tipo brincar, curtir a } \\
\text { vida, passear e coisas do tipo } \\
\text { e a noite para nós descansar, } \\
\text { dormir e acordar novamente. }\end{array}$ & $\begin{array}{l}\text { O dia existe para } \\
\text { acordar e realizar } \\
\text { atividades e a noite } \\
\text { para dormir. }\end{array}$ & $\begin{array}{l}\text { O dia para realizar } \\
\text { atividades e a noite } \\
\text { para dormir. }\end{array}$ & \multirow[t]{2}{*}{$\begin{array}{l}\text { O dia para } \\
\text { realizar } \\
\text { atividades e a } \\
\text { noite para dormir. }\end{array}$} \\
\hline $\begin{array}{l}\text { Y - O dia serve para trabalhar } \\
\text { e brincar e estudar, a noite é a } \\
\text { hora de dormir e a hora mais } \\
\text { silenciosa. }\end{array}$ & $\begin{array}{l}\text { O dia existe para } \\
\text { realizar atividades e } \\
\text { a noite para dormir. }\end{array}$ & $\begin{array}{l}\text { O dia para realizar } \\
\text { atividades e a noite } \\
\text { para dormir. }\end{array}$ & \\
\hline $\begin{array}{l}\mathrm{R} \text { - Porque a terra gira e } \\
\text { involta tem o sol que é o dia } \\
\text { e a noite é a lua. }\end{array}$ & $\begin{array}{l}\text { O dia é o Sol e a } \\
\text { noite é a Lua. }\end{array}$ & $\begin{array}{l}\text { O Sol gera o dia e a } \\
\text { Lua gera a noite. }\end{array}$ & \multirow{2}{*}{$\begin{array}{l}\text { O Sol gera o dia } \\
\text { e a Lua gera a } \\
\text { noite. }\end{array}$} \\
\hline $\begin{array}{l}\mathrm{H}-[\ldots] \text { porque em volta do } \\
\text { planeta Terra tem o sol que é } \\
\text { uma estrela e a lua que é um } \\
\text { satélite natural. }\end{array}$ & $\begin{array}{l}\text { O dia existe porque } \\
\text { em volta da Terra há } \\
\text { o Sol e a Lua. }\end{array}$ & $\begin{array}{l}\text { O Sol gera o dia e a } \\
\text { Lua gera a noite. }\end{array}$ & \\
\hline $\begin{array}{l}\text { G - O dia existe porque se a } \\
\text { gente vivesse só de noite não } \\
\text { ia aguentar tudo escuro, e } \\
\text { também prejudica a visão. }\end{array}$ & $\begin{array}{l}\text { Precisamos da luz } \\
\text { solar para viver e do } \\
\text { escuro para dormir. }\end{array}$ & $\begin{array}{l}\text { A luz para viver e a } \\
\text { escuridão para } \\
\text { dormir. }\end{array}$ & $\begin{array}{l}\text { A luz para viver e } \\
\text { a escuridão para } \\
\text { dormir. }\end{array}$ \\
\hline
\end{tabular}

Fonte: Elaborado pelos autores.

Assim, procedeu-se a ATD (MORAES; GALIAZZI, 2011). Responderam ao pré-questionário 25 estudantes. Os dados obtidos com as respostas dos sujeitos de pesquisa foram agrupados em um único arquivo, codificando-os por letras de modo a distinguir seus enunciados e a preservar suas identidades. A ATD ocorreu conforme explicitado no Quadro 1: desconstrução das respostas dos sujeitos em um ou mais excertos; ressignificação dos excertos, originando unidades de significado; agrupamento das unidades conforme similaridades de significado, emergindo, assim, cinco categorias finais de análise. A saber: $\mathrm{O}$ dia para realizar atividades e a noite 
para dormir; O Sol gera o dia e a Lua gera a noite; Por que a Terra está girando; A luz para viver e a escuridão para dormir; $\mathrm{O}$ dia causa o calor e a noite o frio.

A maioria dos estudantes $(15)^{6}$ respondeu que existe o dia para realizar atividades e a noite para dormir. Nessa categoria, também foram agrupados os excertos dos estudantes que indicavam acreditar que a existência do dia e da noite dependia simplesmente da necessidade do ser humano em descansar à noite, para possuir energia no dia seguinte ao acordar, como é possível perceber na resposta do Estudante S: "A noite serve para nós termos energia para o outro dia e o dia serve para gastar energia para dormir e quando acordamos nós vamos ter energia para gastar outra vez".

Também é considerável a quantidade de estudantes (7) que acreditavam que o Sol gera o dia e a Lua gera a noite. É provável que respondam assim, pois muitos estudantes só conseguem enxergar a Lua durante a noite. O excerto do Estudante R evidencia a emergência dessa categoria: “[...] o sol que é o dia e a noite é a lua.” (Estudante R).

Alguns estudantes (6) responderam que o dia e a noite existem porque a Terra está girando. Nessa categoria, encontram-se os excertos dos estudantes que mais aproximaram-se da realidade em suas respostas. Nenhum utilizou os termos Rotação e Translação para referir-se aos movimentos da Terra. Porém, dois estudantes detalharam o movimento de translação em suas respostas, como é possível observar nos seguintes excertos: "[...] a Terra fica girando em torno do sol" (Estudante I); "Porque a terra gira em volta do sol [...]” (Estudante D). Somente um estudante detalhou o movimento de rotação da Terra em sua resposta, como pode-se constatar no seguinte excerto: "é porque o mundo gira, uma das metades fica virada para o sol e a outra não fica virada para o sol e quando aqui é de noite na outra metade é de dia e vise versa." (Estudante N).

$\mathrm{Na}$ categoria A luz para viver e a escuridão para dormir foram agrupados os excertos de seis estudantes. Esses estudantes, em maioria, responderam que precisamos "[...] da luz para conseguirmos viver" (Estudante L). Viver para esses estudantes refere-se à realização de atividades que fazem acordados. À existência da noite, eles atribuíram a necessidade de haver escuridão para conseguirem dormir.

Somente um estudante respondeu que o dia causa o calor e a noite o frio, como aponta o seguinte excerto de seu texto: "Num dia caloroso o menino disse para a menina: - Que calor quem dera se existisse a noite bem frio por que tá muito calor." (Estudante B). É provável que esse estudante não tenha se lembrado das noites quentes de verão ou dos dias frios de inverno ao responder a pergunta.

A partir dessa análise, foi possível perceber que os estudantes divergiam bastante em suas justificativas para a existência do dia e da noite anteriormente à realização do projeto interdisciplinar, pois das suas respostas à pergunta "Por que existe o dia e a noite?", no préquestionário, emergiram cinco categorias de análise. Além disso, poucos apresentaram respostas de cunho científico e, dentre eles, somente um estudante demonstrou compreender que esse fenômeno ocorre devido à rotação da Terra.

${ }^{6} \mathrm{O}$ numeral entre parênteses indica a quantidade de excertos agrupados na categoria, ressaltando que de uma mesma resposta dada ao questionário, algumas vezes, foram retirados mais de um excerto. 
Após a realização do projeto interdisciplinar, os estudantes responderam novamente à pergunta "Por que existe o dia e a noite?". A análise de suas respostas posteriores ocorreu semelhante à análise de suas respostas prévias.

Para explicitar como a análise foi feita, elaborou-se o Quadro 2, que evidencia as categorias do pós-questionário. Nesse quadro, também serão apresentadas a análise das respostas de apenas cinco estudantes, para que seja compreendido como emergiram cada uma das categorias.

Quadro 2 - Categorias emergentes do pós-questionário

\begin{tabular}{|l|l|l|l|}
\hline \multicolumn{1}{|c|}{ Excertos } & \multicolumn{1}{|c|}{ Ressignificação } & \multicolumn{1}{c|}{$\begin{array}{c}\text { Unidades de } \\
\text { Significado }\end{array}$} & $\begin{array}{l}\text { Categorias } \\
\text { Emergentes }\end{array}$ \\
\hline $\begin{array}{l}\text { E - O dia e a noite existe } \\
\text { porque a Terra gira em torno } \\
\text { de seu eixo. Quando a metade } \\
\text { dela está em um lado é dia, } \\
\text { quando está em outro é noite } \\
\text { e o nome disso é rotação. }\end{array}$ & $\begin{array}{l}\text { O dia e a noite existe } \\
\text { por causa da rotação } \\
\text { que faz a Terra girar } \\
\text { em torno do seu eixo. }\end{array}$ & Rotação da Terra. & Rotação da Terra. \\
\hline $\begin{array}{l}\text { M - A Terra gira no seu eixo } \\
\text { e a Terra em uma metade ela } \\
\text { fica noite e na outra fica dia e } \\
\text { quando vira vai trocando e } \\
\text { isso se chama rotação. }\end{array}$ & $\begin{array}{l}\text { O dia e a noite existe } \\
\text { por causa da rotação } \\
\text { em que a Terra está } \\
\text { girando em torno do } \\
\text { seu eixo. }\end{array}$ & Rotação da Terra & \\
\hline $\begin{array}{l}\text { L - ela [Terra] gira em volta } \\
\text { do sol e a lua gira ao redor da } \\
\text { Terra. }\end{array}$ & $\begin{array}{l}\text { O dia e a noite existe } \\
\text { por que a Terra gira } \\
\text { em torno do Sol. }\end{array}$ & Translação da Terra. & $\begin{array}{l}\text { Translação da } \\
\text { Terra. }\end{array}$ \\
\hline $\begin{array}{l}\text { J - quando a Terra fica de } \\
\text { frente para a lua é noite, e } \\
\text { quando ta de frente para o sol }\end{array}$ & $\begin{array}{l}\text { O dia existe por } \\
\text { causa do Sol e a } \\
\text { noite por causa da } \\
\text { Lua. dia. }\end{array}$ & $\begin{array}{l}\text { O Sol gera o dia e a } \\
\text { Lua gera a noite. }\end{array}$ & $\begin{array}{l}\text { O Sol gera o dia } \\
\text { e a Lua gera a } \\
\text { noite. }\end{array}$ \\
\hline $\begin{array}{l}\text { G - [...] a parte [da Terra] que } \\
\text { está exposta ao sol é dia e a } \\
\text { que esta do lado da lua esta } \\
\text { de noite. }\end{array}$ & $\begin{array}{l}\text { O dia existe por } \\
\text { causa do Sol e a } \\
\text { noite por causa da } \\
\text { Lua. }\end{array}$ & $\begin{array}{l}\text { Fonte Elaborado pelos autores. } \\
\text { Lua gera a noite. }\end{array}$ & \\
\hline
\end{tabular}

Assim, novamente, procedeu-se a ATD (MORAES; GALIAZZI, 2011). Responderam ao pós-questionário 21 estudantes. Os dados obtidos com as respostas dos sujeitos de pesquisa foram agrupados em um único arquivo, codificando-os pelas mesmas letras que lhes foram atribuídas na análise do pré-questionário. A ATD ocorreu conforme explicitado no Quadro 2: desconstrução das respostas dos sujeitos em excertos, aparecendo, novamente, mais de um excerto em algumas respostas; ressignificação dos excertos, originando unidades de significado; agrupamento das unidades conforme similaridades de significado, emergindo assim três categorias finais de análise. A saber: Rotação da Terra; Translação da Terra; O sol gera o dia e a Lua gera a noite.

É possível perceber, de imediato, que, no pós-questionário, as respostas dos estudantes passaram a convergir, pois emergiram apenas três categorias de análise. Além disso, nota-se que os estudantes passaram a apresentar respostas de cunho mais científico, pois categorias do pré-questionário, como, por exemplo, o dia para realizar atividades e a noite para dormir, não 
emergiram no pós-questionário.

Na categoria Rotação da Terra, encontra-se a maior quantidade de excertos (25) o que evidencia que a maioria das respostas dadas pelos estudantes indicava que o dia e a noite existem por causa da rotação da Terra. Inclusive, passaram a utilizar esse termo exato em suas respostas, como observa-se na resposta do Estudante N: "É porque existe a rotação e quando aqui [Brasil] é de noite lá na China é de dia e é por isso que existe o dia e a noite". Nota-se que o Estudante N, mesmo já descrevendo o movimento de rotação da Terra no pré-questionário como justificativa para a existência do dia e da noite, avançou na sua aprendizagem, pois adquiriu conhecimento do nome desse movimento.

Mesmo os excertos dos estudantes que não usaram o termo exato "rotação" também foram agrupados nessa categoria, pois conseguiram descrever o movimento em suas respostas, como é possível verificar nos seguintes excertos: "é quando a Terra gira em torno do seu eixo" (Estudante H); “[...] ela [Terra] gira em torno do seu próprio eixo" (Estudante B). O Estudante B pode ser utilizado como exemplo para representar o avanço que os estudantes tiveram em sua aprendizagem após a realização do projeto interdisciplinar, pois em sua resposta prévia demonstrou acreditar que o dia e a noite existem para haver calor e frio e, na posterior, conseguiu descrever o movimento de rotação da Terra como justificativa para a existência desse fenômeno.

Alguns estudantes conseguiram tanto utilizar o termo rotação quanto descrever detalhadamente esse movimento em suas respostas, como verifica-se no excerto do Estudante O: "Por que a terra gira no seu próprio eixo, e a terra em uma metade ela fica dia e na outra noite e quando ela gira vai trocando, isso se chama rotação" (Estudante $\mathrm{O}$ ).

Alguns estudantes (8) tiveram excertos de suas respostas, indicando que ainda acreditam que o Sol gera o dia e a Lua gera a noite, como, por exemplo, o Estudante R: "[...] uma parte [da Terra] o sol ilumina e a outra a lua." (Estudante R). No entanto, mesmo o Estudante R mantendo um excerto de sua resposta nessa categoria, outros excertos de sua resposta foram categorizados como Rotação. O mesmo ocorreu com excertos de outros estudantes que também se encontram nessa categoria. É provável que esses estudantes tenham tido essa visão, pois no experimento 2215 Sistema Sol, Terra e Lua, explorado durante a visita ao MCT-PUCRS, e nas maquetes que construíram como modelos matemáticos para justificar a existência do dia e da noite, a Lua estava presente mesmo sem ser necessária para a rotação da Terra.

Apenas o Estudante L atribuiu a existência do dia e da noite à translação da Terra. Embora não tenha utilizado o termo exato "translação", é possível perceber no seguinte excerto de sua resposta que está sendo descrito esse movimento: "[...] ela [Terra] gira em torno do sol e a lua gira ao redor da Terra" (Estudante L). Esse estudante também teve um excerto de sua resposta categorizado como Rotação, mas mesmo assim acabou descrevendo o movimento de translação em sua resposta. É provável que essa confusão tenha ocorrido, pois no experimento interativo 2215 Sistema Sol, Terra e Lua do MCT-PUCRS são realizados os movimentos de rotação e de translação da Terra simultaneamente. No entanto, mesmo não apresentando a resposta esperada, percebe-se que houve avanço em sua aprendizagem, pois sua resposta posterior possuiu caráter científico para justificar a existência do dia e da noite, enquanto que em sua 
resposta prévia atribuía a existência desse fenômeno simplesmente à necessidade de haver luz para viver e de escuridão para dormir.

Ao analisar as respostas apresentadas à questão "Por que existe o dia e a noite?" antes e após a realização do projeto interdisciplinar de ensino, foi possível verificar que os estudantes obtiveram avanço significativo em sua aprendizagem. Antes, a maioria acreditava que o dia e a noite existiam simplesmente para haver momentos em que deveriam estar realizando atividades acordados e outros em que deveriam estar dormindo. Ao final do projeto, passaram a apresentar respostas de caráter científico para justificar a existência do dia e da noite. A essa mudança, atribui-se a exploração de experimentos interativos do MCT-PUCRS e a construção de um modelo matemático sob a forma de uma maquete, representando a rotação da Terra. Evidencia-se, assim, a contribuição dessas atividades para a alfabetização científica dos estudantes.

Além disso, como afirmam Galle, Vargas e Lara (2015, p. 54), “[...] os estudantes aprenderam de modo mais aprofundado e complexo tais fenômenos, principalmente devido à desfragmentação das disciplinas durante o desenvolvimento do projeto, tornando-os pesquisadores ao lado de seus professores [...].". Nesse processo os professores assumem o papel de mediadores do processo de aprendizagem (GALLE et al., 2015).

\section{CONSIDERAÇÕES FINAIS}

Com a finalização do projeto interdisciplinar de ensino é possível tecer algumas considerações acerca dos resultados obtidos com a aplicação das atividades previstas.

Em relação ao método de ensino utilizado nessa proposta, a Modelagem Matemática possibilitou aos estudantes desenvolver sua capacidade de pesquisa e sua criatividade para a criação de um modelo. O modelo matemático elaborado pelos estudantes constituiu-se de uma maquete representando o movimento de rotação da Terra e mostrou-se eficaz para responder à questão central de pesquisa "Por que existe o dia e a noite?".

No que concerne à exploração dos recursos disponibilizados pelo MCT-PUCRS como museu interativo, foi verificada sua eficácia para mostrar aos estudantes o real motivo de existência do dia e a noite na Terra. Também, lhes foi possibilitado, por meio dessa exploração, visualizar a presença da Matemática no tema Rotação da Terra.

Anteriormente à realização do projeto, a maioria dos estudantes não apresentava respostas objetivas e de cunho científico para a questão central de pesquisa. Após sua realização, os estudantes demonstraram perceber que o dia e a noite existem devido ao movimento de rotação da Terra. Mesmo os estudantes que não apresentaram essa resposta ao final avançaram em sua aprendizagem, pois passaram a elaborar respostas mais objetivas e científicas para a questão. Atribui-se esse avanço à exploração dos experimentos interativos do MCT-PUCRS e à criação do modelo matemático.

A interdisciplinaridade em que estava fundamentado o projeto foi eficaz para auxiliar os estudantes na melhor visualização e na compreensão do mundo em que vivem, uma vez que 
estão inseridos em um contexto amplo que perpassa os limites de uma única disciplina. A partir da integração de diferentes disciplinas abordadas no projeto, em particular Artes, Ciências, Geografia, Língua Portuguesa e Matemática, os estudantes puderam construir o conhecimento envolvido na pesquisa como um todo e não em partes.

Em relação à Matemática, também foi possível perceber uma apropriação pelos estudantes de sua linguagem, além de uma melhor percepção e visualização acerca de sua presença no cotidiano.

Concluindo, pode-se afirmar que as atividades de caráter interdisciplinar propostas durante a execução do projeto, em particular a exploração de recursos disponibilizados pelo MCTPUCRS e a criação de um modelo matemático, causaram uma mudança significativa na percepção que os estudantes tinham sobre a existência do dia e da noite na Terra, contribuindo assim para sua alfabetização científica. 


\section{REFERÊNCIAS}

BASSANEZI, R. C. Ensino-aprendizagem com modelagem matemática: uma nova estratégia. 3. ed. São Paulo: Contexto, 2009.

BERTOLETTI, A. C. R. A arte de construir experimentos interativos. In: BORGES, R. M. R. (Org.). Museu de Ciências e Tecnologia da PUCRS: coletânea de textos publicados. Porto Alegre: EDIPUCRS, 2013. p. 61-68.

BERTOLETTI, J. J. Museu de ciências e tecnologias da pucrs: projetos especiais - 1967-2007. In: BORGES, R. M. R.; IMHOFF, A. L.; BARCELLOS, G. B. (Org.). Educação e cultura científica e tecnológica: centros e museus de ciências do Brasil. Porto Alegre: EDIPUCRS, 2012. p. 299-358.

BERTOLETTI, J. J. Ações dos museus para a formação do público. In: BORGES, R. M. R. (Org.). Museu de Ciências e Tecnologia da PUCRS: coletânea de textos publicados. Porto Alegre: EDIPUCRS, 2013. p. 19-32.

BIEMBENGUT, M. S. Modelagem matemática no ensino fundamental. Blumenau: Edifurb, 2014.

BIEMBENGUT, M. S.; HEIN, N. Modelagem matemática no ensino. 5. ed. São Paulo: Contexto, 2011.

BRASIL; EDUCAÇÃO, Ministério da; EDUCAÇÃO, Conselho Nacional de. Resolução cne/cp $\mathrm{n}^{0} 1$, de 15 de maio de 2006. institui diretrizes curriculares nacionais para o curso de graduação em pedagogia, licenciatura. Diário Oficial da República Federativa do Brasil, 2006. Disponível em: <http://portal.mec.gov.br/cne/arquivos/pdf/rcp01_06.pdf> Acesso em 11 fev. 2013.

CHASSOT, A. Alfabetização científica: uma possibilidade para a inclusão social. Revista Brasileira de Educação, n. 22, p. 89-100, 2003.

COMITÊ Internacional de Museus - ICOM. Barcelona, 2001. Disponível em: http://www.ufrgs.br/difusaocultural/adminseminario/documentos/arquivo/26_10\%20

Equipamentos\%20culturais\%20Antonio\%20C\%20P\%20Vieira.pdf. Acesso em 22 dez. 2017.

FERRARO, J. L. S.; GIGLIO, R. O museu como espaço de transversalidade. Educação Por Escrito, v. 5, n. 2, p. 333-345, 2014.

GALLE, L. A. V.; VARGAS, J. L. S.; LARA, I. C. M. Modelagem matemática e aerogeradores: Uma possibilidade para interdisciplinaridade na sala de aula. Educação Matemática em Revista, v. 20, n. 47, p. 47-55, 2015.

LARA, I. C. M.; BIEMBENGUT, M. S. Modelagem e etnomatemática nas ciências da natureza e matemática: possibilidades na formação de professores. In: CONGRESO INTERNACIONAL DE ENSENAANZA DE LAS CIENCIAS Y LA MATEMÁTICA, 2011. Anais do I Congreso Internacional de Enseñanza de lasCiencias y la Matemática. Argentina, 2011.

MORAES, R.; GALIAZZI, M. C. Análise textual: discursiva. 2. ed. rev. Ijuí: Editora Unijuí, 2011.

SANTOMÉ, J. T. Globalização e interdisciplinaridade: o currículo integrado. Porto Alegre: Artes Médicas, 1998. 
VALENTE, M. E. A. (Org.). Museus de Ciências e Tecnologia, interpretações e ações dirigidas ao público. Rio de Janeiro: MAST, 2007. 